\title{
DLTS study of deep level defects in Li-ion irradiated bipolar junction transistor
}

\author{
K.V. Madhu ${ }^{\text {a }}$, S.R. Kulkarni ${ }^{\text {b }}$, M. Ravindra ${ }^{\text {c }}$, R. Damle ${ }^{\text {a,* }}$ \\ a Department of Physics, Jnanabharati, Bangalore University, Bangalore 560 056, Karnataka, India \\ ${ }^{\mathrm{b}}$ Department of Physics, Center for PG Studies, SBMJC, Jayanagar, Bangalore 560 011, Karnataka, India \\ ${ }^{\mathrm{c}}$ Components Division, ICG, ISRO Satellite Centre, Airport Road, Bangalore 560 017, Karnataka, India
}

Received 17 June 2006; received in revised form 5 September 2006

Available online 22 November 2006

\begin{abstract}

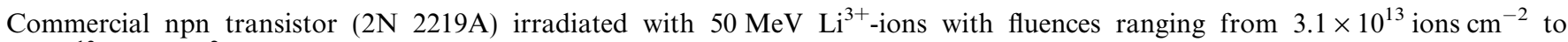
$12.5 \times 10^{13}$ ions $\mathrm{cm}^{-2}$, is studied for radiation induced gain degradation and minority carrier trap levels or recombination centers. The properties such as activation energy, trap concentration and capture cross section of induced deep levels are studied by deep level transient spectroscopy (DLTS) technique. Minority carrier trap levels with energies ranging from $0.237 \mathrm{eV}$ to $0.591 \mathrm{eV}$ were observed in the base-collector junction of the transistor. In situ $I-V$ measurements were made to study the gain degradation as a function of ion fluence. Ion induced energy levels result in increase in the base current through Shockley Read Hall (SRH) or multi-phonon recombination and subsequent transistor gain degradation.
\end{abstract}

(c) 2006 Elsevier B.V. All rights reserved.

PACS: 71.55.-i; 72.20.Jv; 78.70.-g; 61.82.Fk

Keywords: Bipolar junction transistor; Gain degradation; DLTS; Deep level defects; SRH recombination

\section{Introduction}

Bipolar junction transistors are being extensively used in space and other radiation rich environments. It is generally known that devices operating in radiation rich environments display changes in the physical properties and electrical characteristics. It is useful to understand the radiation response of devices to find better design strategies before employing them for specific applications. Considerable amount of data are available on the irradiation effects of $\gamma$-rays, fast neutrons, electrons and protons on semiconductor devices [1-9]. In the recent years, npn transistors have been studied for damage mechanisms by oxygen ion irradiation $[10,11]$. However, there appears to be rather little work on heavy ion induced effects and consequent charac-

\footnotetext{
* Corresponding author. Tel.: +91 80 22961483; fax: +91 8023219295. E-mail address: damleraju@yahoo.com (R. Damle).
}

terization of defects and traps by DLTS technique. DLTS is now an established technique for detecting and characterizing variety of defects in transistors. In the present work, an effort is made to understand the radiation response of npn bipolar junction transistor ( $2 \mathrm{~N}$ 2219A) designed for space applications. The results of in situ $I-V$ measurements as a function of Li-ion fluence as well as DLTS studies are presented to gain an insight into the mechanism of transistor gain degradation. This device has been thoroughly studied in our earlier work for $24 \mathrm{MeV}$ proton, $8 \mathrm{MeV}$ electron and ${ }^{60} \mathrm{Co} \gamma$-rays induced effects [12-14]. However, irradiation with these radiations has failed to exhibit detectable and well behaved DLTS signals.

\section{Experimental details}

Commercial bipolar junction transistor (2N 2219A, npn) manufactured by a technology from Continental 
Device India Ltd. (CDIL) has been selected for the present study. This device is a switching transistor with standard configuration (base thickness is $2.0 \mu \mathrm{m}$ and oxide thickness is $1.2 \mu \mathrm{m}$ ) suitable for low and high frequency operation. Table 1 shows the stopping power and range of ion in matter (SRIM) and transfer of ion in matter (TRIM) calculations for $50 \mathrm{MeV} \mathrm{Li}$ in silicon target. These calculations show that at $50 \mathrm{MeV}$ energy, Li-ions have a projected range in silicon of about $310 \mu \mathrm{m}$ and the displacement damage is expected to be maximum in the base region of the transistor. Decapped transistor is exposed to $50 \mathrm{MeV}$ $\mathrm{Li}^{3+}$-ions using $15 \mathrm{UD} 16 \mathrm{MV}$ pelletron Tandem Van de Graff accelerator facility at Inter-University Accelerator Centre, New Delhi. The transistor in the biased condition (CE mode) is irradiated by $\mathrm{Li}^{3+}$-ions with fluence ranging from $3.1 \times 10^{13}$ ions cm $\mathrm{cm}^{-2}$ to $12.5 \times 10^{13}$ ions $\mathrm{cm}^{-2}$. The ion fluences are calculated by measuring the ion current $(\mathrm{pnA})$ and irradiation time. During irradiation, the target chamber is maintained at room temperature $(300 \mathrm{~K})$ and low pressure $\left(7.5 \times 10^{-9}\right.$ Torr $)$. The ion beam current is fixed at 10 particle nanoampere (pnA). Keithley 236 source meter together with computer interface is used for in situ $I-V$ measurements. Output characteristics of the transistor is studied at a constant base current of $50 \mu \mathrm{A}$. The collector voltage is varied from $-0.1 \mathrm{~V}$ to $5 \mathrm{~V}$ in the steps of $0.01 \mathrm{~V}$. Gummel plots are acquired by varying base voltage from $0 \mathrm{~V}$ to $1 \mathrm{~V}$ in the steps of $0.01 \mathrm{~V}$ at constant collector voltage of $5 \mathrm{~V}$.

DLTS spectra are recorded for both unirradiated transistor and three different transistors of the same batch (date code) exposed to Li-ion for different fluences. The trap concentration, activation energy and capture cross section of different deep levels are determined by DLTS spectra. The DLTS system (IMS-2000) employed for the present study consists of a boxcar averager, a pulse generator, a thousand point digitizer, a voltage generator and a high speed capacitance meter. The pulse generator is capable of generating pulses with widths ranging from $100 \mathrm{~ns}$ to $10 \mathrm{~s}$. The pulse height could be programmed from $-12 \mathrm{~V}$ to $+12 \mathrm{~V}$. The boxcar averager is capable of generating seven rate windows. The time constants can be varied from $1 \mathrm{~ms}$ to $2 \mathrm{~s}$. In the present study, DLTS spectra are recorded with a reverse bias of $4 \mathrm{~V}$ and pulse width of $19.2 \mathrm{~ms}$ applied to base-collector junction.

Table 1

SRIM and TRIM data for $50 \mathrm{MeV}$ Li-ion in silicon

\begin{tabular}{|c|c|c|c|}
\hline $\begin{array}{l}\text { SRIM data for } 50 \mathrm{MeV} \text { Li-ion } \\
\text { Electron energy loss, }\left(\frac{\mathrm{d} E}{\mathrm{~d} X}\right)_{\mathrm{elec}}\end{array}$ & silicon & \multicolumn{2}{|c|}{$9.47 \mathrm{eV} / \AA$} \\
\hline $\begin{array}{l}\text { Nuclear energy loss, }\left(\frac{\mathrm{d} E}{\mathrm{~d} X}\right)_{\text {nuc }} \\
\text { Range }\end{array}$ & & \multicolumn{2}{|c|}{$\begin{array}{l}5.32 \times 10^{-03} \mathrm{eV} / \AA \\
310.24 \mu \mathrm{m}\end{array}$} \\
\hline \multicolumn{4}{|c|}{ TRIM data for different ion fluences } \\
\hline Ion fluence $\left(\times 10^{13}\right.$ ions $\left.\mathrm{cm}^{-2}\right)$ & 3.1 & 9.4 & 12.5 \\
\hline Vacancies $\left(\mathrm{cm}^{-2}\right)$ & $3.4 \times 10^{11}$ & $1.0 \times 10^{12}$ & $1.4 \times 10^{12}$ \\
\hline Replacement Collisions $\left(\mathrm{cm}^{-2}\right)$ & $2.7 \times 10^{8}$ & $8.2 \times 10^{10}$ & $1.1 \times 10^{11}$ \\
\hline Total Displacements $\left(\mathrm{cm}^{-2}\right)$ & $3.7 \times 10^{11}$ & $1.1 \times 10^{12}$ & $1.5 \times 10^{12}$ \\
\hline
\end{tabular}

\section{Results and discussion}

\subsection{In situ measurements of electrical characteristics}

Fig. 1 exhibits the collector characteristics of the transistor as a function of ion fluence. The plot shows that the gain degradation does not vary linearly with ion fluence. For the ion fluence more than $1.2 \times 10^{13}$ ions $\mathrm{cm}^{-2}$, the gain saturates. Figs. 2 and 3 exhibit Gummel plots (variation of $I_{\mathrm{B}}, I_{\mathrm{C}}$ with base voltage $V_{\mathrm{BE}}$ ). It is observed that the base current $I_{\mathrm{B}}$ increases with increasing ion fluence while the collector current decreases with ion fluence. Fig. 4 shows the variation of base and collector currents as a function of ion fluence.

It is well known that the degradation in gain of the transistor can occur due to both increased recombination in the emitter-base region induced mainly by total ionizing dose (TID) and increased recombination in the neutral base (induced mainly by displacement damage). Increased recombination in the base-emitter region does not lead to decrease in the collector current because the number of carriers injected in the base depends on the doping of the base and the applied voltage only. On the other hand, increased recombination in the neutral base leads to an increase in the base current which in turn results in the decrease in the collector current. When recombination centers are generated in the base region of the transistor, it leads to an increase in the base current by decreasing the minority carrier lifetime $[15,16]$. A decrease in the minority carrier lifetime will be reflected in the degradation of the forward current gain of the transistor. Fig. 5 shows the degradation of forward current gain as a function of ion fluence. Thus displacement damage appears to play a major role than total ionizing dose (TID) induced damage in influencing the gain degradation upon Li-ion irradiation.

\subsection{DLTS measurements}

In principle, any ion like lithium can damage transistors through both ionization and displacement. Ionization is a surface phenomenon. Displacement damage is a bulk phenomenon which results in the creation of defects such as vacancy, interstitial, di-vacancy, Frenkel pair, vacancy - impurity complexes namely A-center (V-O), E-center (V-P) and di-interstitial or higher order complexes called D-center [17]. The deep level defects introduced by irradiation of transistors by $\mathrm{Li}^{3+}$-ions are characterized using DLTS technique. DLTS is a high frequency capacitance transient thermal scanning method useful for observing a wide variety of deep defects in semiconductor devices [18]. The DLTS spectrum is a plot of difference in capacitance $(\delta C)$ versus temperature. Fig. 6 exhibits the DLTS spectra of $\mathrm{Li}^{3+}$ irradiated transistor for different ion fluences. The trap concentration $\left(N_{\mathrm{T}}\right)$ can be determined by knowing peak height $\left(\delta C_{\max }\right)$ in the DLTS spectrum. In the DLTS characterization, the capacitance transients of collector-base junction at different temperatures are 


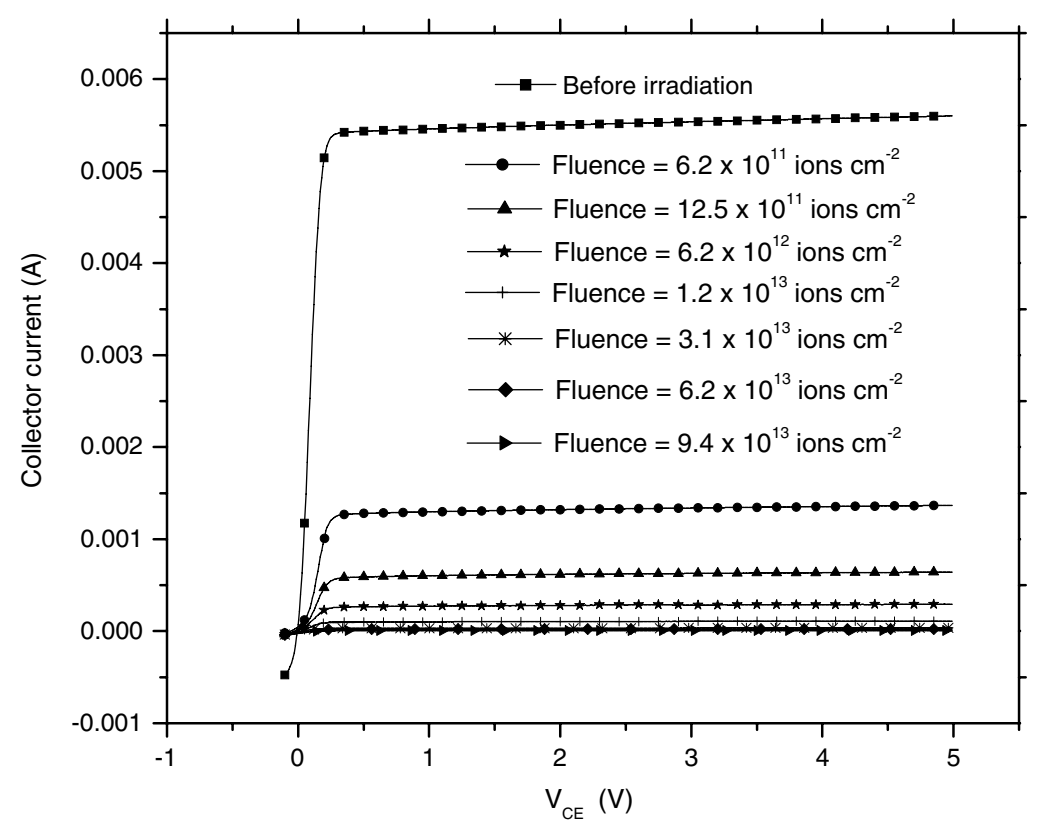

Fig. 1. Collector characteristics of $\mathrm{Li}^{3+}$ irradiated transistor for different ion fluences at constant base current $I_{\mathrm{B}}=50 \mu \mathrm{A}$.

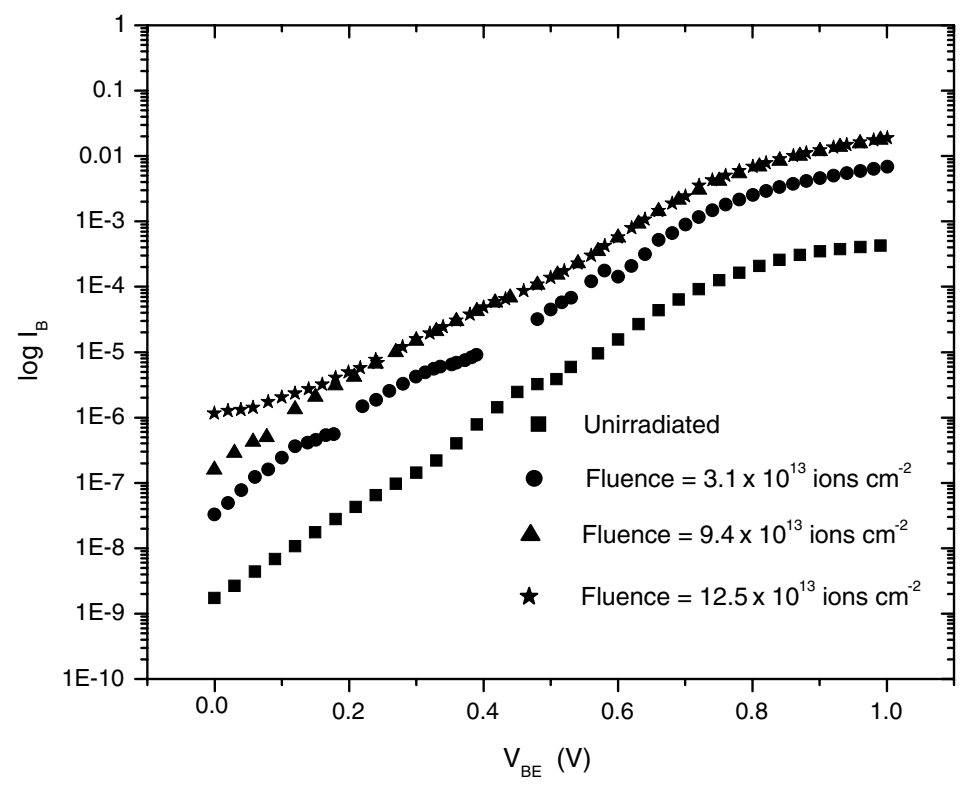

Fig. 2. Variation of base current $I_{\mathrm{B}}$ with $V_{\mathrm{BE}}$ in $\mathrm{Li}^{3+}$ irradiated transistor for different ion fluences $\left(V_{\mathrm{CE}}=5 \mathrm{~V}\right)$.

recorded. The time constant $(\tau)$ for the given capacitance transient, activation energy $\left(E_{\mathrm{C}}-E_{\mathrm{T}}\right)$ and capture cross section $(\sigma)$ of the deep level are related to each other as

$\tau T^{2}=\frac{\exp \left[\left(E_{\mathrm{C}}-E_{\mathrm{T}}\right) / k T\right]}{\gamma \sigma}$,

where $\gamma$ is the material coefficient and all other symbols have usual meaning [19]. A plot of $\ln \left(\tau T^{2}\right)$ versus (1000/ $T$ ) is known as Arrhenius plot, the slope of which yields the activation energy of the trap. The intercept $\ln [1 /(\sigma \tau)]$ gives the capture cross section $(\sigma)$. In the present work, the activation energy and capture cross section for different deep levels are determined as a function of ion fluence. Fig. 7 exhibits the Arrhenius plots of irradiated transistor for three different ion fluences. Three minority carrier deep level defects labeled ED1, ED2 and ED3 are observed in the DLTS spectra of the lithium irradiated transistor with an ion fluence of $3.1 \times 10^{13}$ ions $\mathrm{cm}^{-2}$. Defects labeled $\mathrm{EC} 1, \mathrm{EC} 2$ and $\mathrm{EC} 3$ are observed with an ion fluence of $9.4 \times 10^{13}$ ions $\mathrm{cm}^{-2}$. Defects labeled EF1, EF2 and EF3 are observed with an ion fluence of $12.5 \times 10^{13}$ ions $\mathrm{cm}^{-2}$. The letter $\mathrm{E}$ in the defect label symbolizes an electron trap. 


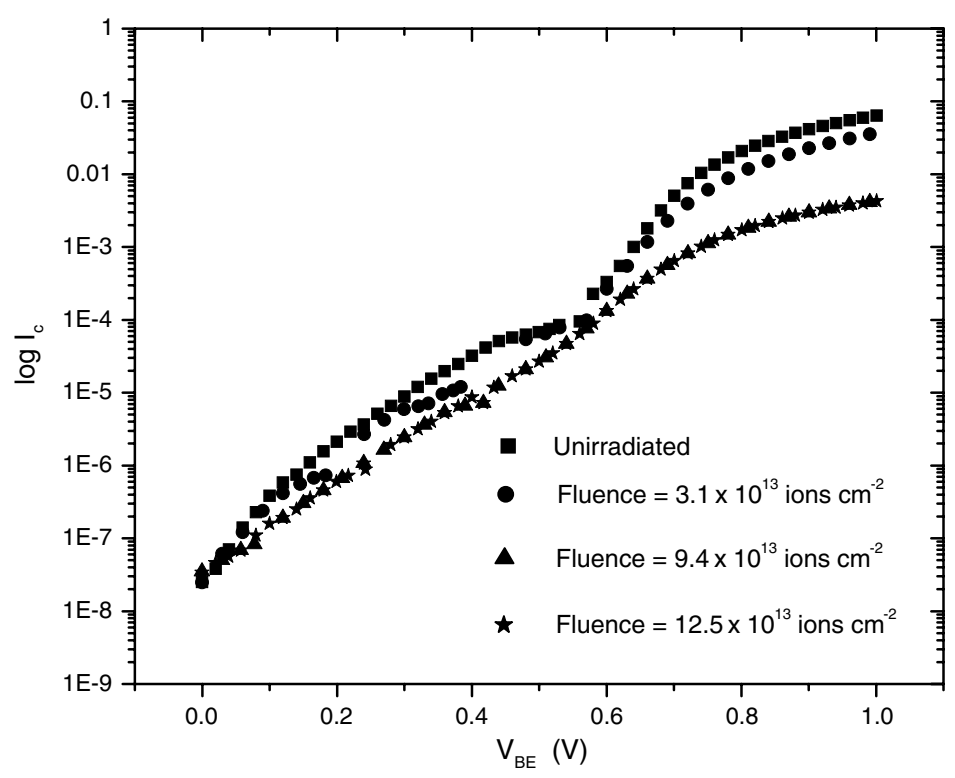

Fig. 3. Variation of collector current $I_{\mathrm{C}}$ with $V_{\mathrm{BE}}$ in $\mathrm{Li}^{3+}$ irradiated transistor for different ion fluences $\left(V_{\mathrm{CE}}=5 \mathrm{~V}\right)$.

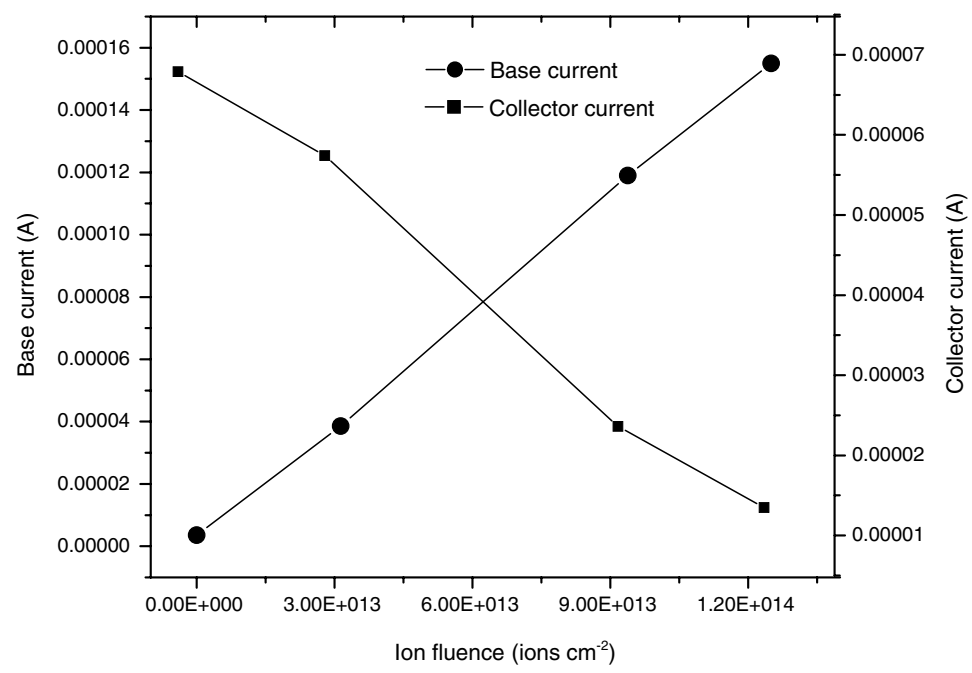

Fig. 4. Variation of base and collector currents as a function of ion fluence. The lines are guide to the eye.

The defect energy level EF2 with an energy of $0.37 \mathrm{eV}$ could be attributed to E-center $[10,11]$. The defect levels ED1 and EC1 with activation energies $0.292 \mathrm{eV}$ and $0.312 \mathrm{eV}$, respectively are attributed to A-centers. The levels EF1, ED2, ED3 and EC2 with energies $0.237 \mathrm{eV}$, $0.417 \mathrm{eV}, 0.458 \mathrm{eV}$ and $0.451 \mathrm{eV}$, respectively are attributed to di-vacancies $[10,20-22]$. The levels EC3 and EF3 with energies $0.591 \mathrm{eV}$ and $0.551 \mathrm{eV}$ are identified as D-centers $[23,24]$.

The type and nature of the defects generated by ionizing radiation depend on energy and fluence. The defects are identified and characterized on the basis of activation energy of the defect levels. The activation energies in $\mathrm{eV}$ are determined to an accuracy of third decimal place. The defects identified and named in Table 2 are well characterized in the literature $[10,11,20-24]$. As can be seen from Table 2, the activation energies of few defect types do not change while the activation energies of few other defects increase as the ion fluence increases. This is clearly demonstrated in the shape of the DLTS spectra for different ion fluences.

In DLTS spectrum, the peak height represents the trap concentration. The concentration of the defects is found to increase as the ion fluence is increased (the values are tabulated in Table 2). The activation energy and capture cross section of the different defects are calculated by using Arrhenius plots (Fig. 7) and tabulated in Table 2. Introduction rate of defects in the semiconductor devices depends on carrier concentration, Fermi-level, recombination, impurities and electrical biasing [25]. Trap concentration $N_{\mathrm{T}}$ and capture cross section are used to calculate the carrier life time corresponding to that defect level $[5,26]$. 


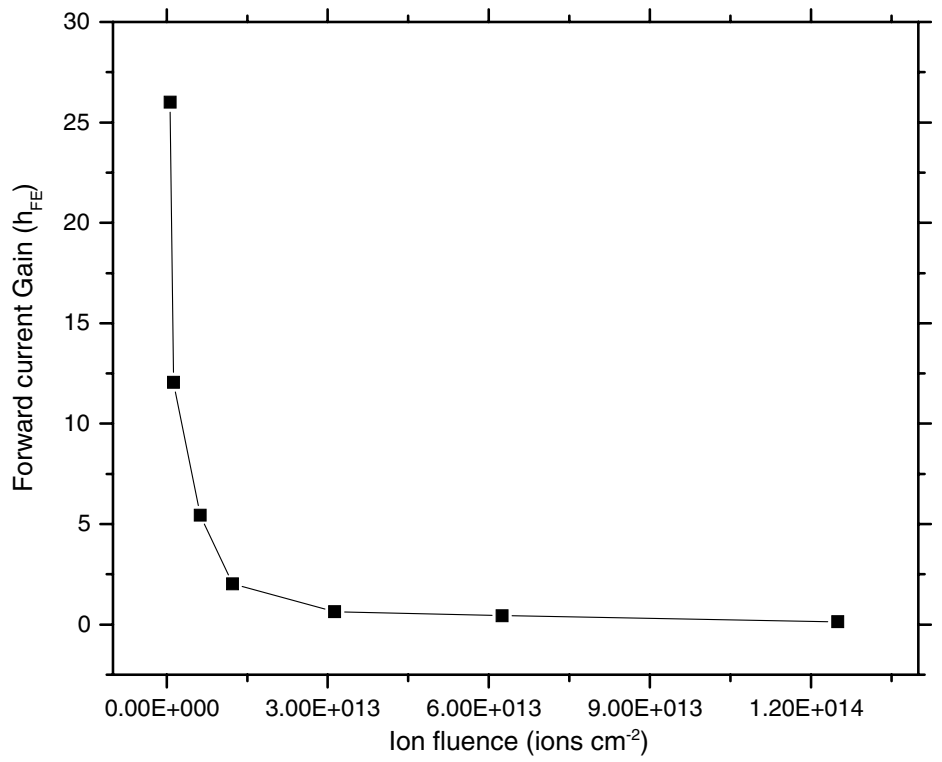

Fig. 5. Current gain degradation as a function of ion fluence.

Table 1 also shows the atomic displacements estimated from TRIM. It is seen that as the ion fluence increases from $3.1 \times 10^{13}$ ion $\mathrm{cm}^{-2}$ to $12.5 \times 10^{13}$ ion $\mathrm{cm}^{-2}$, the number of atomic displacements increases nearly by about five times.
Recombination of electron-hole pairs upon displacement damage is the most important physical phenomenon responsible for the gain degradation. Mainly four kinds of recombination processes are observed in semiconductor

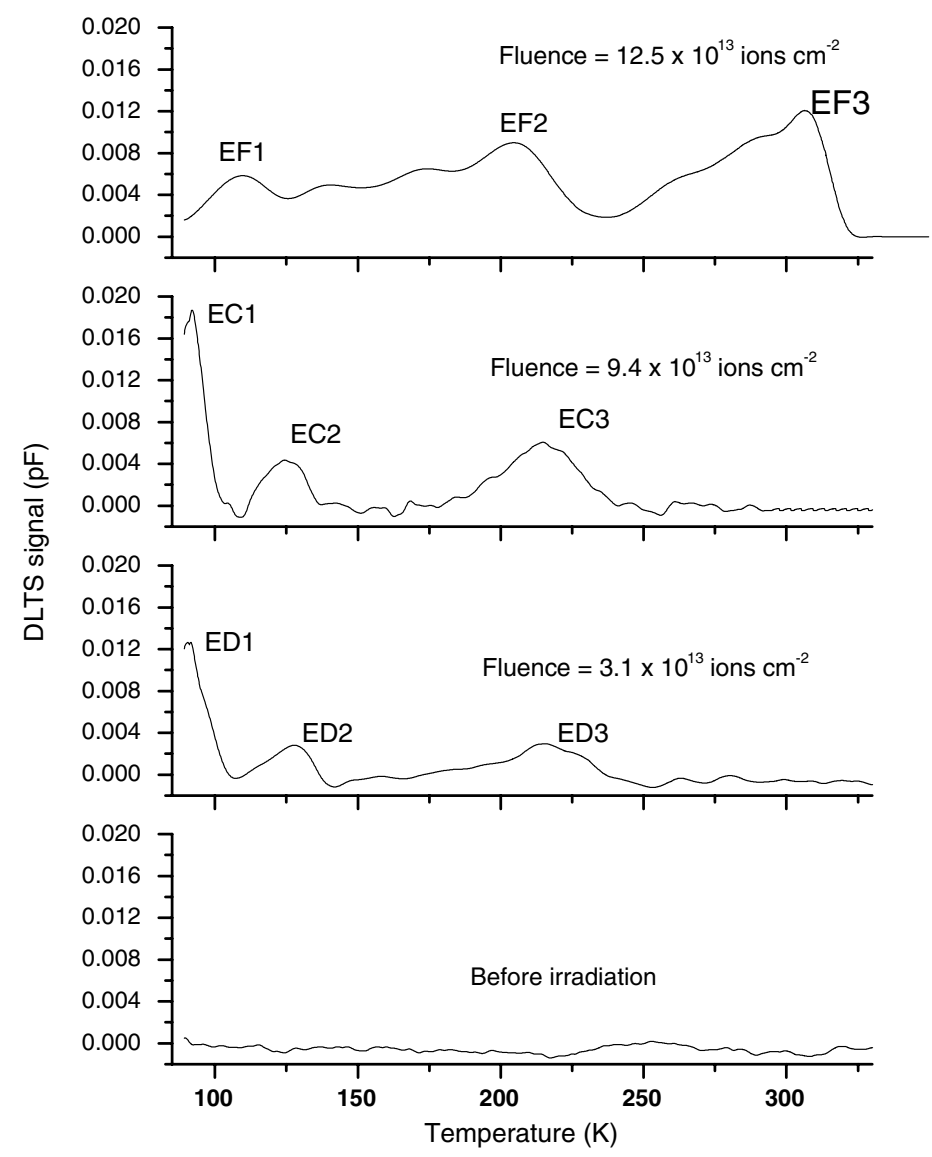

Fig. 6. DLTS spectra of $\mathrm{Li}^{3+}$ irradiated transistor for different ion fluences. Rate window is fixed at $8.3 \mathrm{~s}^{-1}$. 

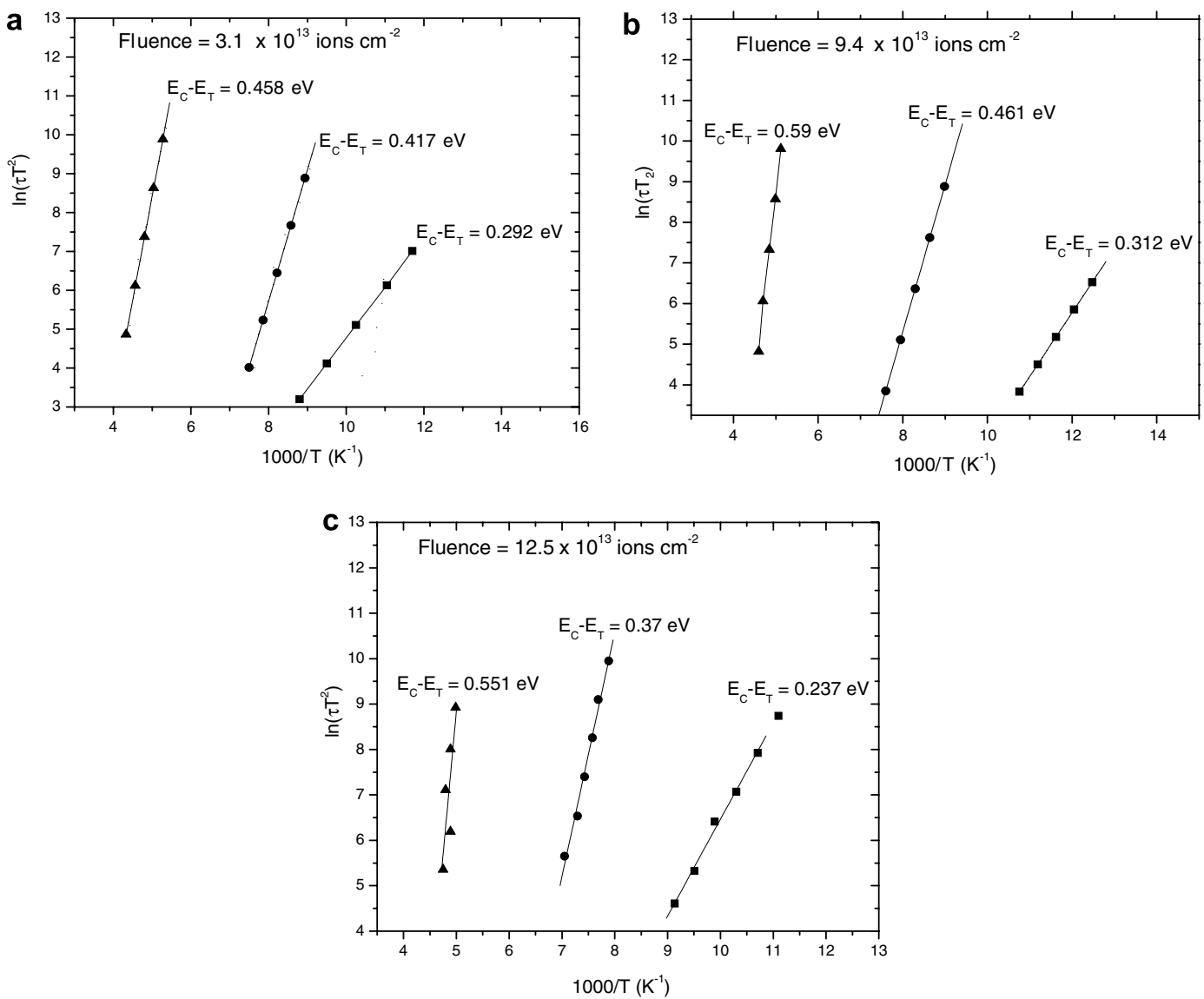

Fig. 7. Arrhenius plots for ion fluence: (a) $3.1 \times 10^{13}$ ions $\mathrm{cm}^{-2}$; (b) $9.4 \times 10^{13}$ ions cm $\mathrm{cm}^{-2}$ and (c) $12.5 \times 10^{13}$ ions cm $\mathrm{cm}^{-2}$.

Table 2

Data obtained from DLTS analysis of irradiated transistor

\begin{tabular}{|c|c|c|c|c|c|c|c|}
\hline $\begin{array}{l}\text { Ion fluence } \\
\left(10^{13} \mathrm{~cm}^{-2}\right)\end{array}$ & $\begin{array}{l}\text { Defect } \\
\text { label }\end{array}$ & $\begin{array}{l}\text { Defect } \\
\text { name }\end{array}$ & $\begin{array}{l}\text { Activation energy } \\
\left(E_{\mathrm{C}}-E_{\mathrm{T}}\right)(\mathrm{eV})\end{array}$ & $\begin{array}{l}N_{\mathrm{T}} \\
\left(10^{13} \mathrm{~cm}^{-3}\right)\end{array}$ & $\begin{array}{l}\text { Capture cross } \\
\text { section }\left(\mathrm{cm}^{2}\right)\end{array}$ & $\begin{array}{l}\text { Introduction } \\
\text { rate } \eta\left(\mathrm{cm}^{-1}\right)\end{array}$ & $\begin{array}{l}\text { Carrier life } \\
\text { time (s) }\end{array}$ \\
\hline \multirow[t]{3}{*}{3.1} & ED1 & $\begin{array}{l}\text { A-center } \\
(\mathrm{V}-\mathrm{O})\end{array}$ & $0.292 \pm 0.003$ & 2.240 & $2.07 \times 10^{-19}$ & 0.72 & $3.47 \times 10^{-02}$ \\
\hline & ED2 & Di-vacancy & $0.417 \pm 0.012$ & 0.472 & $6.14 \times 10^{-14}$ & 0.15 & $4.71 \times 10^{-07}$ \\
\hline & ED3 & Di-vacancy & $0.458 \pm 0.018$ & 0.546 & $2.26 \times 10^{-14}$ & 0.17 & $8.35 \times 10^{-07}$ \\
\hline \multirow[t]{3}{*}{9.4} & $\mathrm{EC} 1$ & $\begin{array}{l}\text { A-center } \\
(\mathrm{V}-\mathrm{O})\end{array}$ & $0.312 \pm 0.005$ & 3.850 & $1.07 \times 10^{-18}$ & 0.39 & $3.91 \times 10^{-03}$ \\
\hline & $\mathrm{EC} 2$ & Di-vacancy & $0.451 \pm 0.017$ & 1.240 & $9.11 \times 10^{-12}$ & 0.13 & $1.21 \times 10^{-09}$ \\
\hline & EC3 & D-center & $0.591 \pm 0.023$ & 1.340 & $4.11 \times 10^{-14}$ & 0.14 & $1.87 \times 10^{-07}$ \\
\hline \multirow[t]{3}{*}{12.5} & EF1 & Di-vacancy & $0.237 \pm 0.002$ & 0.605 & $4.24 \times 10^{-18}$ & 0.05 & $5.67 \times 10^{-03}$ \\
\hline & EF2 & $\begin{array}{l}\text { E-center } \\
(\mathrm{V}-\mathrm{P})\end{array}$ & $0.37 \pm 0.013$ & 6.820 & $1.44 \times 10^{-16}$ & 0.55 & $1.10 \times 10^{-05}$ \\
\hline & EF3 & D-center & $0.551 \pm 0.033$ & 39.00 & $3.5 \times 10^{-13}$ & 3.12 & $6.46 \times 10^{-10}$ \\
\hline
\end{tabular}

devices: (i) Shockley Read Hall or multi-phonon recombination [27-30], (ii) radiative recombination, (iii) Auger recombination and (iv) non-radiative recombination [19]. Radiative recombination is important in direct band gap semiconductors like GaAs. Auger recombination is observed in either direct or indirect band gap semiconductors when the carrier concentration is high. The radiative and Auger recombination lifetimes are defined as [19]
$\tau_{\mathrm{rad}}=\left[B\left(p_{0}+n_{0}+\Delta n\right)\right]^{-1}$,

$\tau_{\text {Auger }}=\left[C_{\mathrm{p}}\left(p_{0}^{2}+2 p_{0} \Delta n+\Delta n^{2}\right)+C_{\mathrm{n}}\left(n_{0}^{2}+2 n_{0} \Delta n+\Delta n^{2}\right)\right]^{-1}$,

where $B$ is the radiative recombination coefficient, $C_{\mathrm{p}}$ and $C_{\mathrm{n}}$ are Auger recombination coefficients. The above equations suggest that both radiative and Auger recombinations are independent of impurity concentrations $\left(N_{\mathrm{T}}\right)$. 
Shockley Read Hall (SRH) or multi-phonon recombination takes place when impurities or deep level defects are present in the semiconductor devices. SRH recombination is particularly important for indirect band gap semiconductors such as $\mathrm{Si}$. SRH recombination life time depends inversely on the defect concentration as

$\tau_{\mathrm{SRH}}=\frac{\tau_{\mathrm{p}}\left(n_{0}+n_{1}+\Delta n\right)+\tau_{n}\left(p_{0}+p_{1}+\Delta n\right)}{\left(p_{0}+n_{0}+\Delta n\right)}$,

where $n_{1}, p_{1}, \tau_{\mathrm{p}}$ and $\tau_{\mathrm{n}}$ are defined as

$n_{1}=n_{i} \exp \left(\frac{E_{\mathrm{C}}-E_{\mathrm{T}}}{k T}\right)$,

$p_{1}=n_{i} \exp \left(\frac{E_{\mathrm{T}}-E_{\mathrm{V}}}{k T}\right)$,

$\tau_{\mathrm{p}}=\left(\frac{1}{\sigma_{\mathrm{p}} V_{\mathrm{th}} N_{\mathrm{T}}}\right)$,

$\tau_{\mathrm{n}}=\left(\frac{1}{\sigma_{\mathrm{n}} V_{\mathrm{th}} N_{\mathrm{T}}}\right)$,

where $V_{\text {th }}$ is the thermal velocity of the electron given by

$V_{\mathrm{th}}=\sqrt{\frac{3 k T}{m_{\mathrm{n}}}}$.

The values of minority carrier lifetimes calculated using above equations and DLTS data are tabulated in Table 2.

\section{Conclusions}

Commercial npn Bipolar Junction Transistor (2N 2219A) undergoes gain degradation upon irradiation by $\mathrm{Li}^{3+}$-ions. Gain degradation does not vary linearly with ion fluence and saturates for fluences above $1.2 \times$ $10^{13}$ ions $\mathrm{cm}^{-2}$. The gain degradation can be attributed to displacement damage in the bulk of the transistor. Deep level defects introduced in the collector-base junction of the transistor are identified as electron traps whose activation energies range from $0.237 \mathrm{eV}$ to $0.591 \mathrm{eV}$. The activation energy, capture cross section and concentration of observed deep level defects are measured using DLTS technique. Comparison of in situ $I-V$ and DLTS measurements reveals that the generation of deep level defects (traps) is responsible for an increase in the base current through Shockley Read Hall (SRH) or multi-phonon recombination and subsequent gain degradation.

\section{Acknowledgements}

Authors thank Mr. R.N. Dutt and Mr. P. Barua IUAC, New Delhi, for their co-operation during the experiment conducted at IUAC, New Delhi. One of the author
(K.V. Madhu) thanks UGC-IUAC for fellowship to carry out the present work. Financial support in the form of ISRO-RESPOND research project is acknowledged. The authors thank Dr. V. Pandian of M/s. Lab Equip. for many helpful discussions.

\section{References}

[1] G.P. Summers, E.A. Wolicki, M.A. Xapsos, P. Marshall, C.J. Dale, M.A. Gehlhauen, R.D. Olice, IEEE Trans. Nucl. Sci. NS-33 (1986) 1282.

[2] H.J. Barnaby, R.D. Schrimpf, A.L. Sternberg, V. Berthe, C. R Cirba, R.L. Peace, IEEE Trans. Nucl. Sci. 48 (2001) 2074.

[3] C.J. Dale, P.W. Marshall, E.A. Burke, G.P. Summers, E.A. Wolicki, IEEE Trans. Nucl. Sci. 35 (1988) 1208.

[4] I. Mandic, V. Cindro, G. Kramberger, E. Kristof, M. Mikum, D. VrtaWnik, Nucl. Instr. and Meth. A 518 (2004) 474.

[5] A. Castaldini, A. Cavallini, L. Rigutti, S. Ferrero, F. Giorgis, J. Appl. Phys. 98 (2005) 053706-1.

[6] J.R. Dekker, A. Tukiainen, R. Jaakkola, K. Vä̈evainen, J. Lammasniemi, M. Pessa, Appl. Phys. Lett. 73 (1998) 3559.

[7] X. Meng, H. Yang, A. Kang, J. Wang, H. Yong, P. Chen, P. Tsein, J. Mater. Sci.: Mater. Electron. 14 (2003) 199.

[8] J.J. Loferski, J. Appl. Phys. 29 (1958) 35.

[9] A. Wei, S.L. Kosier, R.D. Schgrimpf, D.M. Fleetwood, W.E. Combs, Appl. Phys. Lett. 65 (1994) 1918.

[10] A.P. Gnana Prakash, S.C. Ke, K. Siddappa, Semicond. Sci. Technol. 19 (2004) 1029.

[11] A.P. Jnanaprakash, S.C. Ke, K. Siddappa, Nucl. Instr. and Meth. B 215 (2004) 457.

[12] S.R. Kulkarni, A. Sharma, G.R. Joshi, M. Ravindra, R. Damle, Radiat. Eff. Defects Solids 158 (2003) 647.

[13] S.R. Kulkarni, M. Ravindra, G.R. Joshi, R. Damle, Radiat. Eff. Defects Solids 159 (2004) 273.

[14] S.R. Kulkarni, M. Ravindra, G.R. Joshi, R. Damle, Nucl. Instr. and Meth. B 251 (2006) 157.

[15] S.D. Brotherton, P. Bradley, J. Appl. Phys. 53 (8) (1982) 5720.

[16] J.R. Srour, D.M. Long, D.G. Millward, R.L. Fitzwilson, W.L. Chadsey, Radiation Effects on and Dose Enhancement of Electron Materials, Noyes Publications, New Jersey, 1984.

[17] J.R. Srour, Cheryl J. Marshall, P.W. Marshall, IEEE Trans. Nucl. Sci. 50 (2003) 653

[18] D.V. Lang, J. Appl. Phys. 45 (1974) 3023.

[19] D.K. Schroder, Semiconductor Material and Device Characterization, John Wiley \& Sons, 1990, p. 309, 361.

[20] J. Lalita, B.G. Svensson, C. Jasgadish, A. Hallen, Nucl. Instr. and Meth. B 127-128 (1997) 69.

[21] B.G. Svensson, B. Mohadjeri, Phys. Rev. B 43 (1991) 2293.

[22] A.H. Kalma, J.C. Korelli, Phys. Rev. B 173 (1968) 734.

[23] P.K. Giri, Y.N. Mohapatra, Appl. Phys. Lett. 71 (1997) 1682.

[24] P.K. Giri, Y.N. Mohapatra, J. Appl. Phys. 84 (1998) 1901.

[25] P.J. Drevinsky, A.R. Frederickson, D.W. Elsaesser, IEEE Trans. Nucl. Sci. 41 (1994) 1913.

[26] B.G. Rax, A.H. Johnston, T. Miyahira, IEEE Trans. Nucl. Sci. 46 (1999) 1660.

[27] K. Watanabe, C. Munakata, Semicond. Sci. Technol. 8 (1993) 230.

[28] J.C. Pickel, A.H. Kalma, G.R. Hopkinson, C.J. Marshall, IEEE Trans. Nucl. Sci. 50 (2003) 671.

[29] A. Hangleiter, Phys. Rev. B 35 (1987) 9149.

[30] W. Shockley, W.T. Read, Phys. Rev. 87 (1952) 835. 